\title{
Impact of fasting on the presentation and outcome of myocardial infarction during the month of Ramadan
}

\author{
Mohammed Almansori, Ehab Cherif \\ Department of Medicine, Division of Cardiology, University of Dammam, Saudi Arabia
}

\begin{abstract}
Fasting is practiced by millions of Muslims during the month of Ramadan. The available data show that the incidence of acute coronary syndromes during or outside the month of Ramadan is similar. The aim of this study was to evaluate the effects of fasting on acute myocardial infarction. We conducted a chart review to look retrospectively at the effect of fasting on outcomes after acute myocardial infarction in 78 patients (40 patients in the fasting group and 38 patients in the non-fasting group). We found a non-significant difference favoring the fasting state in the degree of elevation of troponin and creatine phosphokinase, but a statistically significant difference favoring the fasting group in the duration of hospital stay after acute myocardial infarction (7.1 \pm 4.3 vs $9.8 \pm 5.3$ days; $\mathrm{P}=0.015$ ). In conclusion, fasting may have a cardio-protective effect on patients with acute myocardial infarction and is associated with shorter hospital stay.
\end{abstract}

\section{Introduction}

Fasting is part of many religions and is practiced by over a billion Muslims worldwide. Fasting has multiple effects on the human body related to the limited amount of time allowed for food and fluid intake, including medications that are important for patients. ${ }^{1,2}$ These effects may also be accompanied with changes in sleep pattern of fasting devotees. Few studies have looked at the incidence of acute myocardial infarction (AMI) during the month of Ramadan and did not show a difference during the period of fasting. In 1999, Temizhan et al. ${ }^{3}$ retrospectively evaluated patients who presented with acute coronary syndrome in Ramadan in the years between 1991 and 1997 and suggested that Ramadan fasting does not in-

\footnotetext{
Correspondence: Mohammed Almansori, Department of Medicine, Division of Cardiology, University of Dammam, PO Box 12875, Dammam 31483, Saudi Arabia.

Tel.: +966.545.30.7447 - Fax: +966.3.896.6741.

E-mail:malmansori@gmail.com
}

Key words: fasting, Ramadan, myocardial infarction, outcome.

Received for publication: 27 April 2013.

Revision received: not required.

Accepted for publication: 6 July 2013.

This work is licensed under a Creative Commons Attribution NonCommercial 3.0 License (CC BY-NC 3.0).

(C) Copyright M. Almansori and E. Cherif, 2014

Licensee PAGEPress, Italy

Italian Journal of Medicine 2014; 8:35-38

doi:10.4081/itjm.2013.240 crease acute coronary heart disease events. In $2004 \mathrm{Al}$ Suwaidi et al. ${ }^{4}$ retrospectively looked at Qatari patients with acute coronary syndrome in the years between 1991 and 2001 and compared those who presented during the month of Ramadan with those presented 1 month before and after the month of Ramadan, They, too, concluded that there was no difference in the incidence of ACS during fasting. They also reported no significant difference in bleeding, stroke or death among their patients. In 2006, Al Suwaidi et al. ${ }^{5}$ looked prospectively into the circadian pattern of acute cardiac events during the fasting state, and reported that fasting patients were less likely to have their symptoms starting between 5-8 a.m. and more likely to have symptoms between 5-6 p.m. and 3-4 a.m. The effect of fasting on the presentation and acute outcomes of AMI is still obscure.

\section{Materials and Methods}

The charts of all patients with a diagnosis of AMI who were admitted during the month of Ramadan to King Fahad University Hospital, Alkhobar, Saudi Arabia from 2007 to 2012 were retrospectively reviewed. Data were collected from the medical records and hospital database. These patients were compared to a group of patients who were admitted with the diagnosis of AMI outside the month of Ramadan. Patients younger than 18 years, non-Muslims and those with charts that had a significant lack of data were excluded. The day was divided into quarters to characterize the time of symptom onset and time of presentation. The two groups were compared with regards to various presentation parameters and acute outcomes. The data and baseline characteristics were computed 
using means and standard deviations for continuous variables and percentages for dichotomous variables. The P-values for the comparisons were calculated using a t-test for continuous data and the chi-square test for dichotomous data.

\section{Results}

Overall, 78 patients were admitted during the study period with a diagnosis of AMI: 40 patients were in the fasting group and 38 patients in the non-fasting group. The baseline characteristics and biochemical profile of the two groups were similar and are summarized in Table 1 and Table 2, respectively. The analysis of different outcome-related parameters on presentation and during the admission are summarized in Table 3. There was a statistically significant difference favoring the fasting state with regards to the duration of hospital stay after AMI $(7.1 \pm 4.3$ vs $9.8 \pm 5.3$ days; $\mathrm{P}=0.015)$. Although some variables, such as cardiac biomarkers, were better in the fasting state, the difference did not reach statistical significance. An analysis of outcomes comparing patients who were admitted in the first and second halves of Ramadan showed that those admitted during the latter period had a statistically significantly higher post-infarct ejection fraction $(41.8 \%$ vs $50 \% ; \mathrm{P}=0.035)$.

\section{Discussion}

Every year, millions of Muslims throughout the world fast during the month of Ramadan. The fasting state causes several metabolic and hormonal adaptations in relation to the reduction in carbohydrate intake through stimulation of gluconeogenesis with a decrease in plasma insulin concentration and increased circulating concentrations of glucagon, catecholamines, growth hormone, thyroid-stimulating hormone and corticosteroids. ${ }^{6,7}$ The incidence of acute coronary syndrome was reported to be similar during and outside the month of Ramadan;, however, data regarding fasting patients with AMI are lacking.

Table 1. Baseline clinical characteristics of the patients.

\begin{tabular}{lccc}
\hline Characteristic & $\begin{array}{c}\text { Fasting group } \\
\text { No. 40 }\end{array}$ & $\begin{array}{c}\text { Non-fasting group } \\
\text { No. 38 }\end{array}$ & P-value \\
\hline Age (mean, SD) years & $51.2(10.7)$ & $50.2(10.2)$ & 0.669 \\
\hline Sex (male) & $87.5 \%$ & $84.2 \%$ & 0.752 \\
\hline Percentage of STEMI & $62.5 \%$ & $63.2 \%$ & 1.000 \\
\hline Diabetes mellitus & $57.5 \%$ & $57.9 \%$ & 1.000 \\
\hline Hypertension & $45.0 \%$ & $52.6 \%$ & 0.651 \\
\hline Smoking & $47.5 \%$ & $55.3 \%$ & 0.507 \\
\hline Dyslipidemia & $52.5 \%$ & $55.3 \%$ & 0.824 \\
\hline Coronary artery disease & $22.5 \%$ & $18.4 \%$ & 0.781 \\
\hline
\end{tabular}

SD, standard deviation; STEMI, ST elevation myocardial infarction.

Table 2. Baseline biochemical profile of the patients.

\begin{tabular}{lccc}
\hline Blood test* & $\begin{array}{c}\text { Fasting group } \\
\text { No. 40 }\end{array}$ & $\begin{array}{c}\text { Non-fasting group } \\
\text { No. 38 }\end{array}$ & P-value \\
\hline Hemoglobin $(\mathrm{g} / \mathrm{dL})$ & $14.0(2.7)$ & $14.0(2.0)$ & 0.988 \\
\hline White blood count $\left(10^{9} / \mathrm{L}\right)$ & $14.6(18.3)$ & $11.9(5.8)$ & 0.372 \\
\hline Creatine $(\mathrm{mg} / \mathrm{dL})$ & $1.1(0.5)$ & $1.1(0.8)$ & 0.397 \\
\hline Blood urea nitrogen $(\mathrm{mg} / \mathrm{dL})$ & $15.4(9.6)$ & $17.8(9.2)$ & 0.263 \\
\hline Serum sodium $(\mathrm{mEq} / \mathrm{L})$ & $138.3(4.1)$ & $137.8(3.5)$ & 0.554 \\
\hline Serum potassium $(\mathrm{mEq} / \mathrm{L})$ & $4.1(0.6)$ & $4.2(0.5)$ & 0.421 \\
\hline Total cholesterol $(\mathrm{mg} / \mathrm{dL})$ & $179.9(45.2)$ & $196.8(52.7)$ & 0.141 \\
\hline Glycosylated hemoglobin $(\%)$ & $9.7(2.5)$ & $7.8(0.4)$ & 0.494 \\
\hline
\end{tabular}

*Data are presented as mean (standard deviation). 
At presentation fasting patients with AMI were noted to have a slower heart rate and lower blood pressure which is explained by the reduction in the sympathetic tone during the fasting state and is supported by previous observations. ${ }^{8}$ Our study showed a nonsignificant difference favoring the fasting state in the degree of elevation in cardiac biomarkers (namely troponin and creatine phosphokinase). This may be attributed to a smaller infarct size during the fasting state which could be explained by the lower levels of inflammatory markers (such as C-reactive protein) during the fasting state, ${ }^{9,10}$ and significant increase in bleeding and coagulation time and a decrease in pla- telet responses to different aggregating agents (adenosine diphosphate, adrenaline and collagen). ${ }^{10,11}$

Figure 1 shows there was no significant difference in time of symptom onset or time of presentation between the two groups. In our study the fasting state was associated with a significantly shorter hospital stay after AMI (7.1 \pm 4.3 vs $9.8 \pm 5.3$ days; $\mathrm{P}=0.015)$ which supports the hypothesis that fasting may have a cardio-protective effect on patients with AMI. Our study has certain limitations, including its retrospective nature and the small sample size. Larger scale studies are, therefore, needed to clarify the effect of fasting on patients with AMI.

Table 3. Differences in outcomes between the fasting and non-fasting group.

\begin{tabular}{lccc}
\hline Outcomes* & Fasting group & Non-fasting group & P-value \\
\hline Heart rate (beats per minute) & $80.8(22.0)$ & $88.7(21.4)$ & 0.112 \\
\hline Systolic blood pressure (mmHg) & $127.9(34.1)$ & $137.7(28.6)$ & 0.177 \\
\hline Diastolic blood pressure (mmHg) & $76.4(20.6)$ & $83.5(18.8)$ & 0.117 \\
\hline Initial troponin (mg/dL) & $7.8(19.8)$ & $10.1(23.9)$ & 0.651 \\
\hline Peak troponin (mg/dL) & $20.5(23.2)$ & $30.7(55.5)$ & 0.290 \\
\hline Initial CPK (mg/dL) & $502.1(1069.0)$ & $812.4(1932.8)$ & 0.380 \\
\hline Peak CPK (mg/dL) & $1774.7(2400.0)$ & $2270.1(3954.0)$ & 0.503 \\
\hline Ejection fraction (\%) & $44.8(11.7)$ & $47.7(10.7)$ & 0.280 \\
\hline Hospital stay (days) & $7.1(4.3)$ & $9.8(5.3)$ & 0.015 \\
\hline In-hospital mortality & $5.0 \%$ & $5.3 \%$ & 1.000 \\
\hline Cardio-pulmonary resuscitation & $10.0 \%$ & $5.3 \%$ & 0.676 \\
\hline Mechanical ventilation & $7.5 \%$ & $7.9 \%$ & 1.000 \\
\hline Blood transfusion & $0 \%$ & $2.6 \%$ & 0.487
\end{tabular}

*Data are presented as mean (standard deviation) or percentage. CPK, creatine phosphokinase.
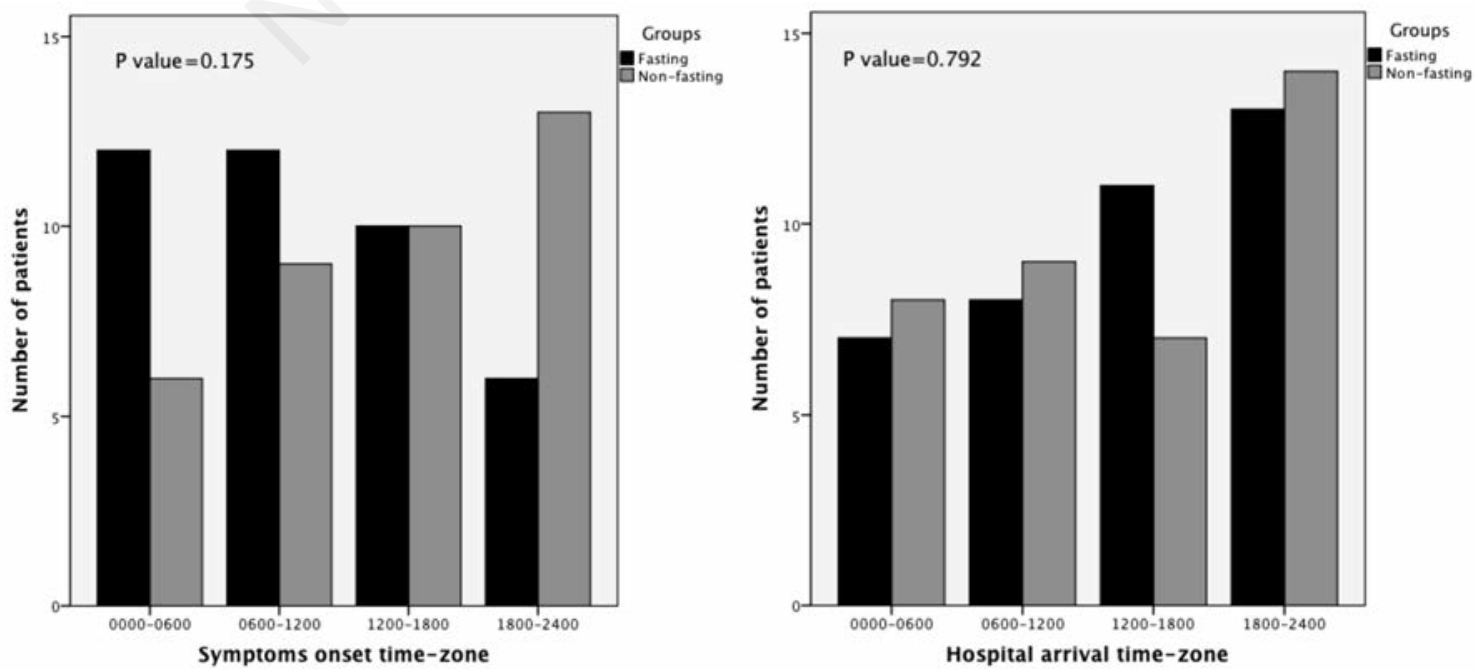

Figure 1. Distribution of patients according to the time of onset of symptoms and arrival in hospital. 


\section{References}

1. Gumaa KA, Mustafa KY, Mahmoud NA, Gader AM. The effects of fasting in Ramadan. 1. Serum uric acid and lipid concentrations. Br J Nutr 1978;40:573-81.

2. Khafaji HA, Bener A, Osman M, et al. The impact of diurnal fasting during Ramadan on the lipid profile, hsCRP, and serum leptin in stable cardiac patients. Vasc Health Risk Manag 2012;8:7-14.

3. Temizhan A, Donderici O, Ouz D, Demirbas B. Is there any effect of Ramadan fasting on acute coronary heart disease events? Int J Cardiol 1999;70:149-53.

4. Al Suwaidi J, Bener A, Suliman A, et al. A population based study of Ramadan fasting and acute coronary syndromes. Heart 2004;90:695-6.

5. Al Suwaidi J, Bener A, Gehani AA, et al. Does the circadian pattern for acute cardiac events presentation vary with fasting? J Postgrad Med 2006;52:30-34.

6. Maughan RJ, Fallah J, Coyle EF. The effects of fasting on metabolism and performance. Br J Sports Med 2010; 44:490-4

7. Galbo H, Richter EA, Hilsted J, et al. Hormonal regulation during prolonged exercise. Ann N Y Acad Sci 1977; 301:72-80.

8. Stokholm KH, Breum L, Astrup A. Cardiac contractility, central haemodynamics and blood pressure regulation during semistarvation. Clin Physiol 1991;11:513-23.

9. Aksungar FB, Topkaya AE, Akyildiz M. Interleukin-6, $\mathrm{C}$-reactive protein and biochemical parameters during prolonged intermittent fasting. Ann Nutr Metab 2007; 51:88-95.

10. Huber R, Nauck M, Basler N, et al. Effects of subtotal fasting on plasmatic coagulation, fibrinolytic status and platelet activation: a controlled pilot study in healthy subjects. Nutr Metab Cardiovasc Dis 2005;15:212-8.

11. Aybak M, Turkoglu A, Sermet A, Denli O. Effect of Ramadan fasting on platelet aggregation in healthy male subjects. Eur J Appl Physiol Occup Physiol 1996;73: 552-6. 